\title{
The HydroGeo Software Package and Its Usage
}

\author{
Ekaterina Dutova ${ }^{1, *}$, Aleksey Nikitenkov ${ }^{1}$, and Konstantin Kuzevanov ${ }^{1}$ \\ ${ }^{1}$ Tomsk Polytechnic University, Geology Division, 634050 Tomsk, av. Lenina, 30, Russia
}

\begin{abstract}
This article presents experience of development and application of the HydroGeo software package used to handle practical and scientific tasks in the field of hydrogeochemistry and hydrogeology. There are examples of its application and basic scientific and practical results.
\end{abstract}

\section{Introduction}

The HydroGeo software package developed by M. B. Bukaty has been widely used by scientists, postgraduates and students of the Siberian Hydrogeochemical School for over 30 years, but it is hardly known in foreign countries. Thus, the purpose of this article is to present its features and provide examples of its application.

Initial versions of the HydroGeo software package were developed by M. B. Bukaty in the late 1970s. They were based on the equilibrium physical and chemical modeling "using the constants of stoichiometric chemical equations" proposed by V. N. Ozyabkin from Russia and H. C. Helgeson (1968) from the USA in the late 1960s. Unlike most of similar projects this one made it possible to take non-ideality of solutions into account within calculations according to K. S. Pitzer's methods and to remove restrictions concerning total dissolved solids. At that time the program was generally used to study geochemistry of strong brines of the Siberian Platform formation of which was enthusiastically and competently studied by Mikhail Boleslavovich Bukaty [1].

In the author's opinion, with increase in the number of calculation blocks the software package became the tool for workstations of hydrogeologists and petroleum hydrogeologists because it combined performance of hydrogeochemical and hydrodynamic calculations most typical for traditional and petroleum hydrogeology, including hydrogeochemical processes in the water-rock system [2].

HydroGeo had been developed and improved within the whole life of Mikhail Boleslavovich till he tragically died. Next versions of the software package were supplemented with numerical simulation of geofiltration and geomigration providing simultaneous solution of tasks in the fields mentioned above within one, two and three dimensions. Range of application of the software package was significantly extended, first of all, due to the tasks concerning geochemistry of radioactive elements and geothermal calculations [3-4].

\footnotetext{
* Corresponding author: Dutova@tpu.ru
} 


\section{Methodology}

Now the HydroGeo software package is about both traditional hydrogeological tasks and key features of deep groundwater and petroleum hydrogeology methods, so it can be widely used in various fields of research and development.

Overview of HydroGeo interface is represented by fig. 1 .

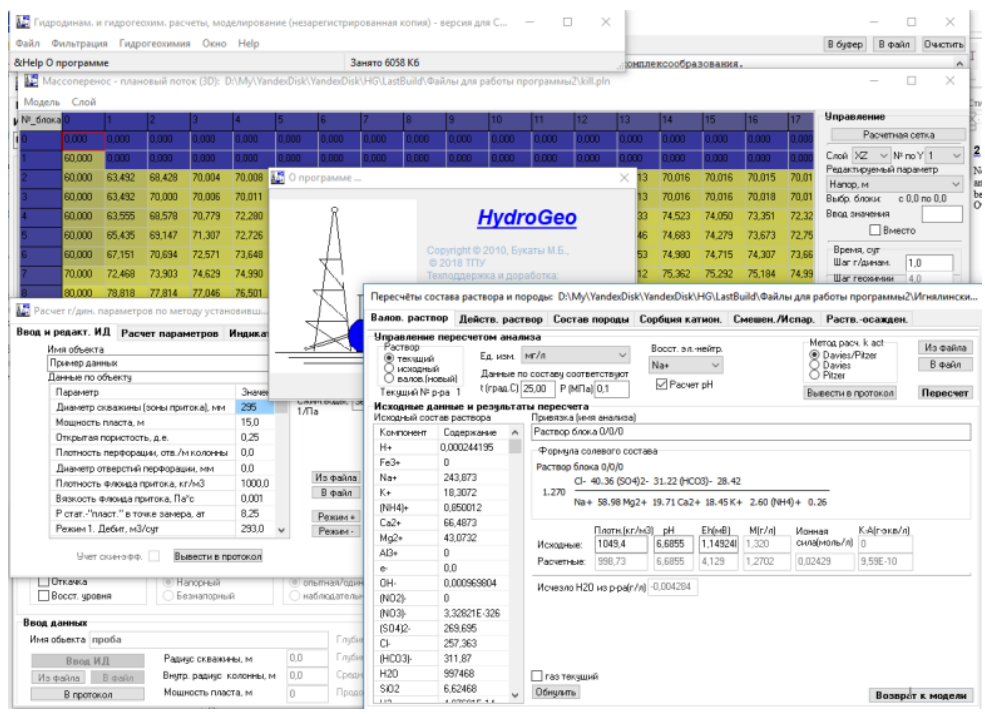

Fig. 1. Some of HydroGeo working windows.

Due to its structure this software package can process information by two main ways: hydrogeochemical and hydrodynamic (fig. 2).

The first one provides adjustment of hydrogeochemical system (addition of solution components and minerals chosen by the user) and performance of different calculations based on the results from chemical analysis of water and rock, including relatively simple conversion of concentration units into virtually any units of measurement, balancing of tests, calculation of $\mathrm{pH}$, activity coefficients according to C.W. Davies or K.S. Pitzer, etc. (including consideration of Eh), and more complicated calculations: modeling of complex formation, calculation of the degree of saturation in relation to the given minerals, modeling of dissolution and precipitation of minerals and salts, mixing and evaporation. Relatively independent part of this block is responsible for performance of calculations and modeling of phase equilibrium in the water-gas system.

The hydrodynamic block provides the opportunity to perform scientific and applicative calculations for evaluation of reservoir rock properties based on the results of filtration tests and experiments in the wells of various applications (processing of data on drainage and filling, injections and emissions, cased hole testing and testing by formation tester in typical and deep wells).

Features of the hydrodynamic block include performance of calculation of groundwater resources on the basis of analytical hydrodynamic method. Calculations of cone of depression for well water inlets and any other well systems are included, and they are suitable for automatic optimization of well placement and well yield according to the criteria stated in advance. Calculation of the productivity of injection wells and their repression fields is available. Calculation of any other water inlets narrowed down to the calculation model "big well" is also available. 


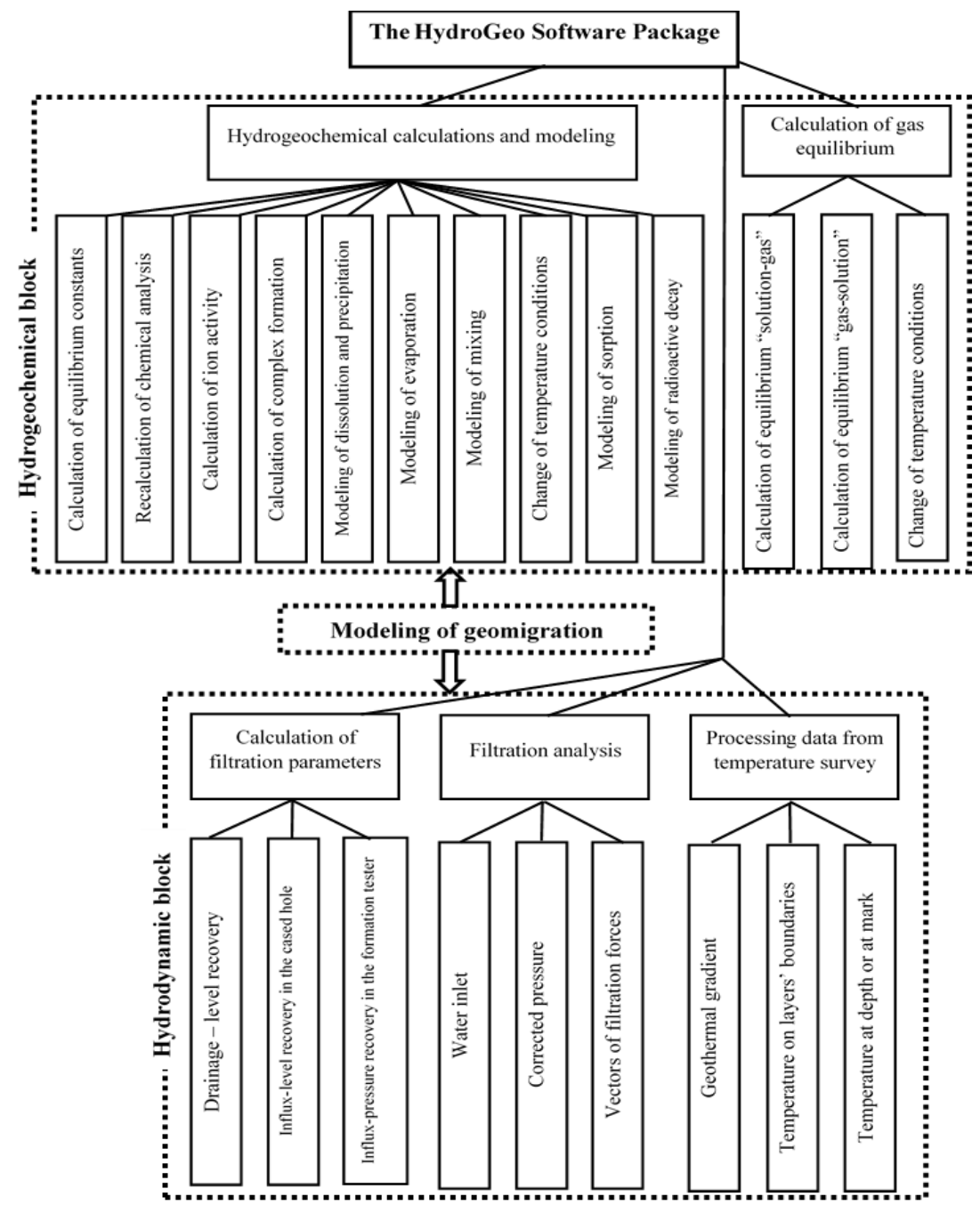

Fig.2. Structure of the HydroGeo software package.

Procedures of hydrodynamic and hydrogeochemical blocks are applied together in the block of geomigration modeling which provides simultaneous solution of tasks in the fields of geofiltration and geomigration within one, two and three dimensions. Since recording of hydrogeochemical processes slows down the calculations sharply, there is a special function of dynamic turning on and off within mixing of aqueous solutions and there is a special feature to turn on and off their interaction with rock, so geomigration task for the stated steps of calculations can be narrowed down to modeling of geofiltration only or to the case when all components of the solution can be considered as conservative elements. The common feature of all software modules is dynamic memory reallocation depending on the current settings and task without any essential restrictions on calculation methods depending on temperature, pressure, total dissolved solids and composition of natural surface and underground water. In addition, recording of data within survey of deep wells provides the opportunity to use the program for traditional hydrogeological works and for petroleum hydrogeology. The software is accompanied by the standard interactive help system. Implementation of the hydrogeochemical block required to create database for thermodynamic parameters of 
components which could be added to the modeled geochemical systems. Now it includes over 4,500 records for components of aqueous solutions and over 1,600 records for compounds of solids. Applied tables include data from a lot of sources (incl. SUPCRT, etc.) and enable the user to choose what he/she considers necesssary for the current task. The program provides direct access to all reference tables used by the program. For this, within its installation on the particular computer the program is automatically installed together with all accompanying files and the latest version of the database (MS Access format). The current information and results of calculation are displayed as the user chooses: in the form of the calculation protocol in some text editor or automatically opened MS Word document.

At present the functional block of the software package is being impoved, including solution to problems revealed within handling non-typical tasks, optimization of computational algorithms and addition of new features concerning data input and output, which will provide more usable interface for the end user.

\section{Results}

A lot of different calculations have been conducted and various environmental and technogenic conditions embracing a wide range of practical and scientific tasks have been modeled for over 30 years of usage of the HydroGeo software package. Finally, analysis of data obtained from these computational experiments has moved theory and practice of hydrogeological and hydrogeochemical research to a quantitative level.

1. Basic factors concerning direction of evolution and self-organization of the waterrock system have been defined. It has been demonstrated that the system is equilibrium and nonequilibrium, self-contradictory, capable of spontaneous, continuous and geologically sustainable development along with creation of entirely new mineral phases and geochemical water types [5-6].

2. Key problems related to formation of highly mineralized underground brines, sodium-, iron-, arsenic-bearing water and other types of water have been solved. New methods of mobilization and concentrating of $\mathrm{Au}, \mathrm{U}, \mathrm{As}, \mathrm{F}, \mathrm{Fe}, \mathrm{Al}, \mathrm{P}, \mathrm{Sr}$ have been revealed and some aspects of the theory concerning formation of stratified, ferromanganese, percolated uranium and placer gold deposits have been updated [7-15].

3. Regional generalizations for hydrogeochemistry and petroleum hydrogeology of the Siberian Platform, the Western Siberian Plate and for geochemistry of groundwater of the Altai-Sayan folded area have been conducted [16-18].

4. Hydrogeochemical and hydrodynamic search and evaluation criteria have been developed for oil, gas and ore deposits and are used to evaluate prospects and explain concepts of development of deposits in the Siberian region [19-21].

5. Forecasts for processes occurring underground and to technological equipment within development of oil, gas and groundwater deposits have been made. Forecast models for processes occurring at the facilities of nuclear industry within wastewater disposal and disposal of liquid radioactive waste in the Siberian Chemical Combine (Seversk) and the Mining and Chemical Combine (Zheleznogorsk) have been developed. Quantitative evaluation for development of radioactive contamination near the former Semipalatinsk Test Site has been conducted [22-23].

\section{Conclusion}

At present the software package is successfully used as a whole or in the form of separate calculation blocks in various research institutions: Institute of Geochemistry 
and Analytical Chemistry of RAS (Moscow), Institute of Geology and Mineralogy, SB of RAS (Novosibirsk), Institute of Petroleum Geology and Geophysics, SB of RAS (Novosibirsk) and its branch (Tomsk), Institute of the Earth's Crust, SB of RAS (Irkutsk), Institute of Natural Resources, Ecology and Cryology, SB of RAS (Chita), Geological Institute, SB of RAS (Ulan-Ude), Scientific Research Institute of MedicalSocial Problems and Management of the Republic of Tuva (Kyzyl), SR Institute of Geology, Geophysics and Mineral Resources (Novosibirsk) and its branches (Krasnoyarsk, Tomsk). Throughout its existence the software package has been regularly used for execution of research works and for educational processes in Tomsk Polytechnic University, Tomsk State University of Architecture and Building, Novosibirsk State University, Tyumen Industrial University.

\section{References}

1. M.B. Bukaty and S.L. Shvartsev, Sov. Geol. 8, 114-123 (1983)

2. M.B. Bukaty, Distribution and Protection of Mineral Resources 2, 37-39 (1997)

3. M.B. Bukaty, Izv. TPU. Geol., Poiski Razv. Pol. Iskop. Sib 305, 348-365 (2002)

4. M.B. Bukaty, M. VNITC 7 (2005)

5. S.L. Shvartsev, V.A. Alekseyev, B. N. Ryzhenko, S.L. Shvartsev, V.P. Zverev, M.B. Bukaty, M.V Mironenko, M.V Charykova, and O.V Chudayev, Geological Evolution and Self-Organization of the Water-Rock System (SB RAS, 2005)

6. S.L. Shvartsev, B. N. Ryzhenko, V. A. Alekseev, E. M. Dutova, I. A. Kondrateva, $\mathrm{G} . \mathrm{Yu}$, Kopylova and O.E. Lepokurova, Geologicheskaya Evolyutsiya i Samoorganizatsiya Sistemy Voda-Poroda (SB RAS, 2007)

7. M.B. Bukaty, Geology and Geophysics 36, 105-114 (1995)

8. S.L. Shvartsev and E.M. Dutova, Geol. Rudn. Mestorozhdeniy 43, 224-233 (2001)

9. L.B. Zamana and M.B. Bukaty, Reports Acad. Sci. 396, 235-238 (2004)

10. E.M. Dutova, M.B. Bukaty, A.I. Nevol'ko, D.S. Pokrovsky, and S.L. Shvartsev, Geology and Geophysics 47, 364-376 (2006)

11. O.L. Gaskova, M.B. Bukaty et al., Geology and Geophysics 50, 115-126 (2009)

12. M.B. Bukaty, E.M. Dutova, A.A. Balobanenko, and K.I. Kuzevanov, Prospect Prot. Miner. Resour. 11, 49-54 (2010)

13. E. M. Dutova and A.N. Nikitenkov, Bulletin of Tomsk State University 330, 202$208(2010)$

14. S.Ivanova, O.E. Lepokurova, O. S. et al., Water Resour. 41, 163-177 (2014)

15. S.L. Shvartsev, L.V Zamana, A.M. et al., Geochemistry Int. 53, 713-725 (2015)

16. E.M. Dutova, A.N. Nikitenkov, V. D. Pokrovskiy, D. Banks, B. S. Frengstad, and V. P. Parnachev, J. Environ. Radioact. 178-179, 63-76 (2017)

17. M.B. Bukaty, Geology and Geophysics 40, 750-763 (1999)

18. S.V Alekseev, L.P. Alekseeva, S.L. Shvartsev, N.S. Trifonov, and E.S. Sidkina, Geochemistry Int. 55, 442-456 (2017)

19. M.B. Bukaty, Geology and Geophysics 50, 1201-1217 (2009)

20. D.A. Novikov and N.S. Trifonov, Arab. J. Geosci. 9, 63-79 (2016)

21. I.V. Vologdina, E.M. Dutova, et al. D.S. Pokrovsky, V. D. Pokrovsky, and I. V. Radyuk, Vestnik of St. Petersburg University. Earth Sciences 3, 58-72 (2015) 
22. V.A. Zuev, M.B. Bukaty, and R.R. Khafizov, Geoecology, Engineering Geology, Hydrogeology, Geocryology 6, 531-546 (2008)

23. M.V. Mishchenko, M.B. Bukaty, and E.M. Dutova, Izv. TPU 319, 167-172 (2011) 